\title{
Alcohol Consumption And Policy Perception Among College Freshman Athletes
}

Ronald D. Williams, Jr., PhD, CHES, Mississippi State University, USA

\begin{abstract}
College athletes consume more alcohol and experience more alcohol-related consequences than non-athlete populations. Freshman athletes are at an even higher risk for alcohol-related problems as they learn to deal with the demands of college athletics. Researchers have suggested that the development of appropriate alcohol policy may be a useful strategy to reduce alcohol problems among athletes; however, study results are inconclusive. The purpose of this study was to examine the impact of team, athletic department, and university policy on college athletes' alcohol consumption. A survey of 263 college freshman athletes from two NCAA universities measured alcohol consumption and perception of alcohol policies at the university, athletic department, and team levels. Results indicated that athletes who abstain from alcohol were more likely to believe in strong enforcement and the desire for greater policy restrictions at the university, athletic department, and team levels. Results also revealed differences in alcohol consumption patterns between team vs. individual sports. These findings suggest a need to develop extensive, strictly enforced alcohol policies to influence alcohol behavior of college freshman athletes.
\end{abstract}

Keywords: Alcohol; Social Ecology; College; Athletes

\section{INTRODUCTION}

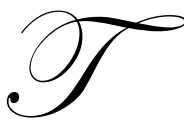

he 2006 NCAA report on substance use indicated that binge drinking among college athletes was increasing (NCAA, 2006). Despite being targeted with alcohol education more often than nonathletes, athletes still report higher alcohol consumption rates and experience more negative consequences such as DUI, unsafe sexual behaviors, and criminal offenses (Hildebrand, Johnson, \& Bogle, 2001; Leichliter, Meilman, Presley, \& Cashin, 1998; Nelson \& Wechsler, 2001; Wechsler, Davenport, Dowdall, Grossman, \& Zanakos, 1997; Williams \& Belcher, 2007; Yusko, Buckman, White, \& Pandina, 2008). This represents a major concern for both university and athletic department administrators in terms of athlete wellbeing and public perception. Due to the often high campus and community visibility of student-athletes, alcohol incidents are considered newsworthy thereby impacting not only the athletes, but the institution as well (Naughton, 1996). While certainly necessary, the education and prevention efforts designed for athletes have not been noticeably effective in reducing alcohol use.

In efforts to improve prevention efforts, researchers have attempted to explain this high risk alcohol behavior by examining the unique personal, social, and environmental influences which are experienced by college athletes (Williams, et al., 2006; Williams et al., 2008; Williams, Perko, Evans, \& Barnes, 2009; Williams \& Barnes, 2010; Yusko et al., 2008). It is theorized that athletes experience distinctive multifarious influences which differ drastically from their non-athlete counterparts including sport-related anxiety, time restraints, and over-reliance on the athletic department support staff (Martens, Dames-O'Connor, \& Beck, 2006). It has also been suggested that freshman athletes are more prone to the impact of such influences because they are inexperienced at dealing with the demands of college athletics (Giacobbi, et al., 2004). More acutely, these influences exist at both the micro (personal attitudes, values, beliefs) and macro (peer norms, teammate expectancies, alcohol policies) levels (Hildebrand et al., 
2001; Leichliter et al., 1998; Thombs, 2000; Wechsler et al., 1997; Williams, et al., 2006; Williams, et al., 2008). The social ecology model provides a useful framework to examine these varying influences as it allows for an examination of intrapersonal, interpersonal, institutional, community, and policy factors which may influence college athletes' alcohol behaviors (Williams, et al., 2006).

The National Institute of Alcohol Abuse and Alcoholism's Task Force on College Drinking released a 2002 call to action identifying college athletes as a high-risk population for alcohol problems (NIAAA, 2002). The NIAAA supports the use of an ecological framework to address campus alcohol issues. Williams and colleagues (2006) proposed the Social Ecology Model for College Athletes' Alcohol Use (SEMCAAU) as a health behavior planning model designed to explore systematic levels of influence which may contribute to alcohol consumption among college athletes. While the SEMCAAU elicits areas of impact for prevention and intervention programming to help reduce alcohol use among college athletes, of particular interest to this study were the subsequent findings on alcohol policy. It has been suggested that the role of the university and athletic department should be explored (Hildebrand et al., 2001; Nelson \& Wechsler, 2001; Thombs, 2000; Williams \& Barnes, 2010). However, there seems to be a body of conflicting research on the policy influence related to college athlete's alcohol use. Williams, et al. (2008) suggested that team, athletic department, and university policies on alcohol had little or no effect on the athlete's alcohol use, while other research indicates that such policies may indeed reduce alcohol consumption (Bower \& Martin, 1999; Lewis, 2008).

Broad policy and programmatic strategies, known as environmental management, are present at almost every college and university in the U.S. (DeJong \& Langford, 2002; DeJong, Towvim, Schneider, 2007). Despite the efforts in education through programmatic initiatives, researchers have suggested that the most effective approach to address alcohol problems on campus may be through effective policy development and enforcement (Saltz \& DeJong, 2002). The Center for College Health and Safety (2005) recommends policy development and enforcement for effective alcohol prevention on campuses, yet determining the true effect of policy on alcohol behaviors among college students is difficult because of the varying policy guidelines at different institutions (Mitchell, Toomey, Erickson, 2005). Furthermore, the conflicting research on policy influences among athletes raises the concern of whether the policy development will have any impact on this high risk population. While college athletes fall under the same policy guidelines and restrictions as non-athlete students at a given school, they may also be bound by regulations set by the athletic department and/or head coach. The purpose of this study was to examine the impact of team, athletic department, and university policy on college athletes' alcohol consumption.

\section{METHODS}

Because freshman are at higher risk for alcohol-related problems and freshman athletes experience are less prepared to deal with athletic demands, this study focuses on a freshman population (Giacobbi, et al., 2004; Harford, Wechsler, \& Muthen, 2003).A non-random sample of 263 freshman college athletes from two NCAA Division 1 universities participated in this study. Athletes were asked to participate as part of a general athletic assembly in the spring semester; however, no athletic department staff or team coach was present during survey administration. Previous research attempted to develop and validate a social ecological instrument called the College Athlete Alcohol Survey to measure alcohol influences on college athletes (Williams et al., 2008). This study utilized a modified version of the College Athlete Alcohol Survey which contained questions related to consumption patterns and perceptions of campus alcohol policies.

Demographic measures included sex, age, on/off-campus residency, and sport type. For sport type, participants were asked to identify if they played an individual or team-based sport. A team sport was identified as one in which the athletic event requires multiple athletes from the same team to participate simultaneously in order to accurately complete the competition; examples are baseball, basketball, football, soccer, softball, and volleyball. An individual sport is one in which a single athlete may complete a given event; examples are cross country, golf, gymnastics, swimming and diving, tennis, and track and field. This distinction was made because the IRB board at one participating institution would not approve the survey identifying specific sports or race/ethnicity. While the race/ethnicity item was dropped completely, the sport type measure was changed to team vs. individual sport, earning IRB approval. In addition to demographics, alcohol use and policy perception measures were collected. Participants were asked to report frequency and quantity of alcohol use by identifying the average number of days 
per week that they consume alcohol and the average number of drinks they have on a usual day. Participants were also asked to identify the average number of drinks consumed per week. To measure policy perceptions, three scales (one each for university, athletic department, and team) were used. Each scale consisted of four items related to policy awareness and enforcement, as well as the participant's agreement with the policy and its enforcement. Cronbach's alpha was used to measure internal consistency of each policy scale and each was determined to be reliable (university, $\alpha=.7182$; athletic department, $\alpha=.7700$; team, $\alpha=.7213$ ).

\section{RESULTS}

The majority of the sample was male $(63.5 \%)$, lived on-campus $(83.3 \%)$, and participated in a team sport (69.2\%). Mean age was 18.7 years (males=18.7; females=18.6). Using the NIAAA guidelines for safe drinking, participants were categorized by drinking level into abstainer $(n=63)$, moderate drinker $(n=88)$, and heavy drinker $(\mathrm{n}=112)$ based on their responses to the alcohol use questions. The guidelines suggest that a heavy drinker is a male who reports drinking more than fourteen drinks per week or four drinks per occasion; or a female who reports drinking more than seven drinks per week or more than three drinks per occasion. A moderate drinker is defined as a male who reports alcohol consumption, but drinks fewer than fourteen drinks per week and four drinks per occasion; or a female who consumes alcohol, but drinks fewer than seven drinks per week and three drinks per occasion (Chen, Dufour, \& Yi, 2003). Table 1 provides demographic differences by drinking level.

Table 1. Demographic Differences among College Athlete Drinking Levels $(n=263)$

\begin{tabular}{|l|c|c|c|c|}
\hline & $\begin{array}{c}\text { Abstainer } \\
\mathbf{n}(\boldsymbol{\%})\end{array}$ & $\begin{array}{c}\text { Moderate } \\
\mathbf{n}(\boldsymbol{\%})\end{array}$ & $\begin{array}{c}\text { Heavy } \\
\mathbf{n}(\boldsymbol{\%})\end{array}$ & $\begin{array}{c}\text { Chi-Square } \\
\chi^{\mathbf{2}}(\mathbf{p})\end{array}$ \\
\hline Male (n=167) & $51(30.5)$ & $48(28.7)$ & $68(40.7)$ & \\
Female (n=96) & $12(12.5)$ & $40(41.7)$ & $44(45.8)$ & $11.698(.003)$ \\
\hline On-campus (n=219) & $48(21.9)$ & $70(32.0)$ & $101(46.1)$ & \\
Off-campus (n=34) & $11(32.4)$ & $12(35.3)$ & $11(32.4)$ & $2.735(.255)$ \\
\hline Team Sport (n=182) & $43(23.6)$ & $55(30.2)$ & $84(46.2)$ & \\
Individual Sport (n=81) & $20(24.7)$ & $33(40.7)$ & $28(34.6)$ & $3.648(.161)$ \\
\hline
\end{tabular}

\section{Alcohol Consumption}

As anticipated, a one-way ANOVA indicated significant differences between all three drinking levels in average days per week of alcohol consumption, average drinks per day when drinking, and average number of total drinks each week (Table 2). Moderate drinkers reported consuming alcohol just over one day per week, while heavy drinkers reported consuming alcohol just less than two days per week. Although the number of consumption days is not considerably different, there is a more pronounced difference in the amount consumed. While abstainers (Ab) consumed no alcohol, heavy drinkers (Hd) consumed 7.10 drinks per consumption day and 13.34 drinks each week and moderate drinkers (Md) consumed 2.39 drinks per consumption day and 2.52 drinks each week.

Table 2. One-way ANOVA of Mean (SD) Drinking Measures among Different Drinking Levels

\begin{tabular}{|l|c|c|c|c|}
\hline & Abstainer & Moderate & Heavy & F (P Value) \\
\hline Days/week of alcohol consumption & $0.0(0.0)$ & $1.27(0.840)$ & $1.76(0.819)$ & $114.420(.000)$ \\
\hline Drinks/day when consuming alcohol & $0.0(0.0)$ & $2.39(0.836)$ & $7.10(3.927)$ & $158.312(.000)$ \\
\hline Mean drinks/week & $0.0(0.0)$ & $2.52(1.912)$ & $13.34(12.350)$ & $70.043(.000)$ \\
\hline
\end{tabular}

Multivariate analysis of variance (MANOVA) was used to determine interaction of demographic (sex, residency, sport type) and alcohol use items. Of the seven interactions, only two significantly affected alcohol use among the participants. Univariate analyses revealed that alcohol use was affected by sex (Wilks' $\lambda=.983, \mathrm{~F}(3$, $243)=5.310, p=.001, \eta^{2}=.062$ ) and the interaction of sex and sport type (Wilks' $\lambda=.964, F(3,243)=3.243, p=.032$, $\left.\eta^{2}=.036\right)$. Males and females reported similar averages in days per week of alcohol consumption $(\mathrm{m}=1.17 ; \mathrm{f}=1.20)$; however, males reported higher drinks per day $(m=4.05 ; \mathrm{f}=3.57)$ and drinks per week $(m=7.66 ; \mathrm{f}=4.55)$. As shown in Table 3, team sport participants of both sexes were significantly higher in all three drinking measures which supports previous research by Hsii, Carlson, and Peebles (2011). 
Table 3. Interactions of Sex and Sport Type on Drinking Measures

\begin{tabular}{|l|l|c|c|c|}
\hline \multirow{2}{*}{ Participant Sex } & \multicolumn{1}{|c|}{ Sport Type } & $\begin{array}{c}\text { Mean Drinks Per } \\
\text { Week }\end{array}$ & $\begin{array}{c}\text { Mean Consumption } \\
\text { Days Per Week }\end{array}$ & Mean Drinks per Day \\
\hline \multirow{2}{*}{ Male } & Team & 8.34 & 1.31 & 4.17 \\
\cline { 2 - 5 } & Individual & 5.50 & 0.73 & 3.68 \\
\hline \multirow{2}{*}{ Female } & Team & 5.55 & 1.42 & 4.07 \\
\cline { 2 - 5 } & Individual & 3.22 & 0.90 & 2.87 \\
\hline
\end{tabular}

\section{Policy Perceptions}

Policy perceptions were not significantly affected by sex, residency, or sport type, but differences were observed among different drinking levels. One-way ANOVAs indicated significant differences between drinking level and each policy scale - university policy $(\mathrm{F}=7.881 ; \mathrm{p} \leq 0.001)$, athletic department policy $(\mathrm{F}=5.162 ; \mathrm{p}=0.006)$, and team policy $(\mathrm{F}=3.108 ; \mathrm{p}=0.046)$. Chi-square analyses revealed that $\mathrm{Ab}(53.6 \%)$ and $\mathrm{Hd}(50.9 \%)$, were more likely than $\mathrm{Md}(35.2 \%)$ to report that university alcohol policies were strictly enforced $\left(\chi^{2}=19.223 ; \mathrm{p}=0.014\right)$. $\mathrm{Ab}$ were least likely to report that athletic department $\left(\mathrm{Ab}=47.6 \%, \mathrm{Md}=59.1 \%, \mathrm{Hd}=77.7 \% ; \chi^{2}=59.449 ; \mathrm{p} \leq 0.001\right)$ and team policies $\left(\mathrm{Ab}=55.6 \%, \mathrm{Md}=67.1 \%, \mathrm{Hd}=73.0 \% ; \chi^{2}=37.446 ; \mathrm{p} \leq 0.001\right)$ were strictly enforced.

Participants were asked if the alcohol policies at all three levels needed to be strengthened. Ab were more likely to report the need for greater policy restrictions on alcohol use at the university level $(\mathrm{Ab}=34.9 \%, \mathrm{Md}=15.9$, $\left.\mathrm{Hd}=2.7 \% ; \chi^{2}=44.153 ; \mathrm{p} \leq 0.001\right)$, athletic department level $\left(\mathrm{Ab}=47.6 \%, \mathrm{Md}=19.6 \%, \mathrm{Hd}=4.5 \% ; \chi^{2}=70.596 ; \mathrm{p} \leq 0.001\right)$, and team level $\left(\mathrm{Ab}=28.6 \%, \mathrm{Md}=13.6 \%, \mathrm{Hd}=7.1 \% ; \chi^{2}=34.733 ; \mathrm{p} \leq 0.001\right)$.

\section{DISCUSSION}

Universities and athletic departments should be concerned about alcohol consumption among freshman college athletes; however, there is promise in the policy strategy for prevention. This study indicated that freshmen athletes are influenced by the policies set forth at the university, athletic department, and team levels. Drinking rate is correlated to perceptions of policy enforcement therefore universities, athletic departments, and head coaches should seek to develop and strongly enforce appropriate alcohol policies. In all policy categories except university policy enforcement, abstainers were more likely to believe that policies were not strictly enforced and believe that greater restrictions are needed in alcohol policies. This result is similar to research on the non-athlete college population which show that support for strong alcohol policies in inversely related to the frequency and quantity of alcohol consumption (Lavigne, Witt, Wood, Laforge, \& DeJong, 2008).

While the development of appropriate alcohol policy is needed at the university, athletic department, and team levels, it must be accompanied with consistent and strong enforcement. The NCAA does not have a standard alcohol policy to which all athletes at member institutions must adhere; however, the organization has set a minimum guideline that all member institutions create a written alcohol, tobacco, and other drug policy (NCAA, 2010). Perhaps the NCAA should explore the development of organization-wide alcohol policies which set minimum standards of behavior. While this may be an idealistic approach considering the culture of alcohol in college athletics, it would set standards for expected behavior and enforcement guidelines.

\section{LIMITATIONS}

The limitations of this study must be considered. While the sample limited and obtained from only two universities, the results do serve as an early indication of the needed research on alcohol policies and the impact on athlete behavior. The data was collected using a cross-sectional design, whereas longitudinal studies may provide a better indicator of the direct behavioral influence. Despite the limitations, this study can serve as a call to action to research the impact of alcohol policies on college freshman athletes. 


\section{ACKNOWLEDGEMENT}

Approved for publication as Journal Article No. J-12064 of the Mississippi Agricultural and Forestry Experiment Station, Mississippi State University.

\section{AUTHOR INFORMATION}

Dr. Ronald Williams, Jr. is an Assistant Professor in the Department of Food Science, Nutrition, and Health Promotion at Mississippi State University. He has extensively researched issues in substance abuse including college alcohol use, tobacco prevention and cessation, and smoke-free policy implications. Dr. Williams has secured multiple grants and contracts for substance abuse prevention projects totaling over $\$ 1.5$ million. As a Certified Health Education Specialist, Dr. Williams has expertise in program evaluation and has served as lead evaluator on multiple substance abuse prevention and treatment programs. E-mail: rwilliams@fsnhp.msstate.edu

\section{REFERENCES}

1. Bower, B., \& Martin, M. (1999). African-American female basketball players: An examination of alcohol and drug behaviors. Journal of American College Health, 48, 129-133.

2. Center for College Health and Safety. (2005). Addressing alcohol use on campus. Retrieved July 29, 2011 from http://www.campushealthandsafety.org/alcohol/campus/.

3. Chen, C., Dufour, M., \& Yi, H. (2003). Alcohol consumption among young adults ages 18-24 in the United States: Results from the 2001-2002 NESARC Survey. Retrieved February 28, 2006 from http://pubs.niaaa.nih.gov/publications/arh 284/269-280.htm.

4. DeJong, W. \& Langford, L.M. (2002). A typology for campus-based alcohol prevention: moving toward environmental management strategies. Journal of Studies on Alcohol, S14, 140-147.

5. DeJong, W., Towvim L.G., \& Schneider, S.K. (2007). Support for alcohol-control policies and enforcement strategies among U.S. college students at 4-year institutions. Journal of American College Health, 56(3), 231-236.

6. $\quad$ Giacobbi, P. R., Lynn, T. K., Wetherington, J. M., Jenkings, J., Bodendorf, M., \& Langley, B. (2004). Stress and coping during the transition to university for first-year female athletes. The Sport Psychologist, 18, 1-20.

7. Harford, T. C, Wechsler, H., \& Muthen, B. O. (2003). Alcohol-related aggression and drinking at offcampus parties and bars: A national study of current drinkers in college. Journal of Studies on Alcohol, 64, 704-711.

8. Hildebrand, K., Johnson, D., \& Bogle, K. (2001). Comparison of patterns of alcohol use between high school and college athletes and non-athletes. College Student Journal, 35, 358-365.

9. Hsii, A., Carlson, J., \& Peebles, R. (2011). Athletic participation and substance use in university students. Journal of Adolescent Health, 48(2), S69-S70.

10. Lavigne, A.M., Witt, C.F., Wood, M.D., Laforge, R., \& DeJong, W. (2008). Predictors of college student support for alcohol control policies and stricter enforcement strategies. American Journal of Drug and Alcohol Abuse, 34, 749-759.

11. Leichliter, J., Meilman, P., Presley, C., \& Cashin, J. (1998). Alcohol use and related consequences among students with varying levels of involvement in college athletics. Journal of American College Health, 46, 257-262.

12. Lewis, T. (2008). An explanatory model of student-athlete drinking: The role of team leadership, social norms, perceptions of risk, and coaches' attitudes toward alcohol consumption. College Student Journal, 42(3), 818-831.

13. Mitchell, R.J., Toomey, T.L., \& Erickson, D. (2005). Alcohol policies on college campuses. Journal of American College Health,53(4), 149-157.

14. National Collegiate Athletic Association (2010). NCAA minimum guidelines for institutional alcohol, tobacco, and other drug education programs. Retrieved August 1, 2011 from http://www.ncaa.org/wps/wcm/connect/c8df9180437ce913bc21be6bcdc87ae7/ATOD+Guideline+2010.pdf ?MOD=AJPERES\&CACHEID=c8df9180437ce913bc21be6bcdc87ae7. 
15. National Collegiate Athletic Association. (2006). NCAA study of substance use habits of college studentathletes. Retrieved May 9, 2011 from http://www.ncaapublications.com/productdownloads/SAHS06.pdf

16. National Institute on Alcohol Abuse and Alcoholism. (2002). A call to action: Changing the culture of drinking at U.S. colleges. NIH Pub. No. 02-5010. Bethesda, MD.

17. Nelson, T. \& Wechsler, H. (2001). Alcohol and college athletes. Medicine and Science in Sports and Exercise, 33, 43-47.

18. Naughton, J. (1996). Alcohol abuse by athletes poses big problems for colleges: Some educators say that sports programs are 'a center of binge drinking.' The Chronicle of Higher Education, 43(2), A47.

19. Saltz, R. \& DeJong, W. (2002). Reducing Alcohol Problems on Campus: A Guide to Planning and Evaluation. U.S. Department of Health and Human Services, National Institute on Alcohol Abuse and Alcoholism. Rockville, MD.

20. Thombs, D. (2000). A test of perceived norms model to explain drinking patterns among university student athletes. Journal of American College Health, 49, 75-83.

21. Wechsler, H., Davenport, A., Dowdall, G., Grossman, S., \& Zanakos, S. (1997). Binge drinking, tobacco, and illicit drug use and involvement in college athletics: A survey of students at 140 American colleges. Journal of American College Health, 45, 195-200.

22. Williams, R., Perko, M., Evans, M. W., \& Barnes, J. (2009, March). Perceptions of alcohol attitudes on campus among college athletes. Oral session presented at the American Alliance for Health, Physical Education, Recreation, and Dance National Convention, Tampa, FL.

23. Williams, R. \& Barnes, J. (2010, March). College athletes' perceptions of university and athletic department alcohol policies. Oral session presented at the American Alliance for Health, Physical Education, Recreation, and Dance National Convention, Indianapolis, IN.

24. Williams, R. \& Belcher, D. (2007). Alcohol-related social and personal problems of undergraduate college students [Abstract]. Research Quarterly for Exercise and Sport, 78 (1), A37.

25. Williams, R., Perko, M., Belcher, D., Leaver-Dunn, D., Usdan, S., \& Leeper, J. (2006). Use of Social Ecology Model to address alcohol use among college athletes. American Journal of Health Studies, 21, 228-237.

26. Williams, R., Perko, M., Usdan, S., Leeper, J., Belcher, D., \& Leaver-Dunn, D. (2008). Influences on alcohol use among NCAA athletes: Application of the Social Ecology Model. American Journal of Health Studies, 23(3), 151-159.

27. Yusko, D.A., Buckman, J.F., White, H.R., \& Pandina, R.J. (2008). Alcohol, tobacco, illicit drugs, and performance enhancers: A comparison of use by college student athletes and nonathletes. Journal of American College Health, 57, 281-290. 